\title{
An assessment of dairy herd bulls in southern Australia: 1. Management practices and bull breeding soundness evaluations
}

\author{
A. S. Hancock, ${ }^{*}{ }^{1}$ P. J. Younis, $\dagger$ D. S. Beggs, ${ }^{*}$ P. D. Mansell, ${ }^{*}$ M. A. Stevenson, ${ }^{*}$ and M. F. Pyman ${ }^{*}$ \\ *Faculty of Veterinary and Agricultural Sciences, The University of Melbourne, Werribee, Victoria 3030, Australia \\ †The Vet Group, Timboon, Victoria 3268, Australia
}

\begin{abstract}
In the pasture-based, seasonally calving dairy herds of southern Australia, the mating period usually consists of an initial artificial insemination period followed by a period of natural service using herd bulls. Bull breeding soundness evaluations (BBSE) were performed on 256 bulls from 32 dairy herds in southwest Victoria, using guidelines produced by the Australian Cattle Veterinarians, before and immediately after a single natural mating period. At the same time, herd managers were questioned regarding the management of the bulls. The objectives of this study were to describe the management practices of dairy herd bulls; to describe the causes of increased risk of reduced fertility in dairy herd bulls, as measured by a standard BBSE; and to describe the reasons for bull removal by herd managers during mating. At the premating BBSE, 19.5\% of bulls were classified as high risk of reduced fertility, mostly due to physical abnormalities and reduced semen quality. At the postmating BBSE, $36.5 \%$ of bulls were classified as high risk of reduced fertility, mostly due to physical abnormalities, primarily lameness. Of the bulls used, $15.9 \%$ were removed from normal mating use by the herd manager, predominantly due to lameness and injuries. A premating BBSE is recommended in dairy herd bulls to identify bulls at risk of reduced fertility. Lameness is the most common problem in dairy herd bulls during the natural mating period, and risk factors associated with lameness in these bulls should be identified to better manage herd bulls.
\end{abstract}

Key words: dairy herd bull, bull breeding soundness evaluation, lameness, seasonally calving herd

\section{INTRODUCTION}

The majority of dairy herds in southern Australia (predominately winter rainfall, temperate climate) are

Received October 6, 2015.

Accepted August 22, 2016.

${ }^{1}$ Corresponding author: a_s_hancock@hotmail.com managed so that cows calve as a group, which allows herd energy requirements to coincide with the timing of maximum pasture growth; they are made up of roughly equal proportions of seasonally calving herds and split calving herds. In seasonally calving herds, a mating start date is defined as 1 gestation length (typically 282 d) before the desired calving start date of the herd manager, and the mating period lasts for a predetermined number of weeks with no matings allowed outside of this period. Split- or batch-calving herds have 2 or 3 mating periods, with start dates defined by the herd manager and no matings allowed outside of the mating periods. Herds that have cows calving continuously throughout the year are referred to as year-round calving herds. Fertility is a key driver of the profitability of any dairy herd (De Vries, 2006), and, due to the finite period in which cows need to resume cycling and conceive, pressure is placed on reproductive performance in seasonally calving herds (Roche et al., 2007). In contrast to year-round calving herds, where the period from calving to confirmed conception is used to measure reproductive performance, in seasonally calving herds the key indicators of reproductive performance focus on the proportion of the herd that conceived within the defined periods following the start of the mating period (e.g., 6-wk in-calf rate, 12 - and 21-wk not-in-calf rate; Morton, 2010). The mating period(s) usually consist of an initial AI period followed by a period where herd bulls are run with the milking herd on a continuous basis to perform natural service (these will be referred to as dairy herd bulls). Replacement heifers for these herds are usually kept from the offspring produced by AI, with calves sired by the herd bull sold shortly after birth. Therefore, the purpose of the herd bull is initiating lactation, not genetic gain.

The reproductive performance of Australian dairy herds has been in steady decline in recent decades. In the largest study of its type in Australia, in split- and seasonally calving dairy herds between 2000 and 2009 there was a decline of approximately $1 \%$ per year in the 6 -wk in-calf rate, with similar declines in reproductive performance as measured by 12 - and 21 -wk not-in-calf 
rates; these figures reflect a general decline with no single explanatory factor (Dairy Australia, 2011). An important implication from these trends is that in seasonally or split-calving herds there are increasingly more cows that are not in-calf to AI, and therefore a greater proportion of the herd presented to the herd bulls in the subsequent natural mating period.

The purpose of the bull breeding soundness evaluation (BBSE) is to assess the ability of a bull to seek out, mount, and serve estrous females and, subsequently, impregnate them. The BBSE assesses risk of reduced fertility of the bull on the day of evaluation. The Australian Cattle Veterinarians (ACV), a special interest group of the Australian Veterinary Association, has developed a standard format for the BBSE (Beggs et al., 2013). Five major components of such a BBSE can include general physical evaluation and examination of the reproductive tract; scrotal circumference measurement; crush-side semen assessment; laboratory assessment of sperm morphology; and serving ability assessment. It is common in dairy situations, where paddocks are small and bulls mounting cows during the season can be observed, to omit the serving ability part of the evaluation because the risks of disease spread and poor animal welfare outcomes outweigh the benefits of the examination results.

The applications of a BBSE have been extensively reviewed in the beef industry, and a BBSE is easily performed, repeatable, and associated with the subsequent fertility of the bull. Several authors have correlated characteristics included in a BBSE with bull fertility (Coulter and Kozub, 1989; Farin et al., 1989; Holroyd et al., 2002; Menegassi et al., 2011). The BBSE has been shown to have a direct, short-term economic benefit to beef producers (Nöthling and Irons, 2008), with the return on investment for performing a BBSE in a commercial beef herd being as high as $\$ 19$ per dollar spent (Menegassi et al., 2011). Whereas no comprehensive cost-benefit analysis of the BBSE has been performed in the dairy industry, n Tasmanian study, using Australian industry benchmarks, predicted a return on investment of nearly $\mathrm{A} \$ 9$ for every dollar spent on performing a BBSE (Dwyer, 2013a).

Few studies have reported BBSE findings from dairy bulls, and those studies report findings from bulls where the semen is collected for AI rather than bulls intended for natural service (Andersson and Alanko, 1992; Foote et al., 1977; Hoflack et al., 2006) or in dairy breeds used in a beef system (Makarechian et al., 1987). Previous studies focus on factors relating to semen quality, and the application of these findings to natural service bulls used in dairy herds is of limited value. The fertility (Overton and Sischo, 2005; Lima et al., 2009) and cost (Overton, 2005; Lima et al., 2010) of dairy herd bulls has been reported in studies from other countries, but the use of these bulls was different than the Australian dairy herd context. Few reports exist regarding management practices of dairy herd bulls, and these are not peer-reviewed papers (Risco et al., 1998, 2011; Champagne et al., 2002; Chenoweth et al., 2003; Dwyer, 2013a,b). Only been a handful of studies have collected pre- and postmating BBSE findings in beef herds (Smith et al., 1981; Boyd et al., 1989, 1991; Godfrey and Lunstra, 1989; Ellis et al., 2005), and to our knowledge no studies have reported on dairy herds. The findings of these studies vary, and due to the differences in bull use between beef and dairy industries, their relevance to the dairy industry is limited.

In the context of dairy herd bulls in seasonally calving herds in southern Australia, the current study was designed to investigate dairy bull management practices, the causes of reduced fertility in dairy herd bulls, the causes of bull removal by herd managers during mating, and possible associations between bull management practices and bull fertility. To achieve these goals, pre- and postmating BBSE were performed and the results were interpreted in conjunction with an evaluation of bull management practices. In this, the first of 2 companion papers, the management practices of dairy herd bulls, the results of the pre- and postmating BBSE, and the causes of bull removal during mating in the study population are discussed.

\section{MATERIALS AND METHODS}

\section{Animals and Herds}

This study was composed of 2 cross-sectional studies ( 1 before and 1 after the natural mating period) of natural-mating bulls in 32 herds. Commercial dairy herds were selected from the client base of The Vet Group, a veterinary practice servicing a large area of southwest Victoria, Australia. The practice services approximately 450 herds and the study herds appeared broadly representative of the practice herds with respect to herd size, breed, and calving pattern. Eligible herds were seasonally or split-calving herds that were planning to use dairy herd bulls with their milking herd for a period that immediately followed a period of AI. Study herds were selected on the basis of convenience, being approached for involvement in the study by the corresponding author through various channels; these included direct contact while providing unrelated veterinary services, through word of mouth via other veterinarians in the practice, and through advertising in the practice newsletter.

Bulls eligible for the premating BBSE were bulls that the herd manager planned to use in the upcoming natu- 
ral mating period following AI. Only bulls that were to be used with the milking herd were selected for evaluation, and bulls that were to be used exclusively with the maiden heifers were not eligible. For the postmating BBSE, the same bulls, providing that they had been used during the mating period, were re-evaluated as soon as possible after the end of the mating period.

\section{BBSE and Risk Classifications}

Both the pre- and postmating BBSE were performed in accordance with the guidelines set out in the publication Veterinary Bull Breeding Soundness Evaluation (Beggs et al., 2013). A classification of low risk, qualified, or high risk was given for each of the following components: physical, crush-side semen, and sperm morphology. These classifications are explained in more detail in Table 1. An overall classification of low risk, qualified, or high risk was then given for the bull. The overall risk classification was determined by the highest risk category given for each of the 3 components. For example, if a bull had a high-risk classification for 1 or more of the 3 components, then the overall classification was high risk; if a bull had no high-risk classifications but had qualified for 1 or more components, then the overall classification was qualified. If all 3 components were classified as low risk, then low risk was the overall classification. The elements of each BBSE were conducted according to the following ACV recommendations.

Scrotal Circumference Measurement. A minimum cutoff of 32 and $34 \mathrm{~cm}$ of scrotal circumference was used to define low risk in bulls aged $2 \mathrm{yr}$ or less and greater than $2 \mathrm{yr}$, respectively. These values were based on the ACV guidelines used for bulls of nonspecified breed (Beggs et al., 2013). Bulls not meeting the thresholds were classified as qualified for physical.

General Physical Evaluation and Examination of the Reproductive Tract. A systematic physical examination was performed and any abnormality detected was assessed to determine whether it was likely to affect the reproductive function of the bull during the mating period. The reproductive organs evaluated were the scrotal sac and its contents, the penis, sheath and prepuce, and the internal genitalia (seminal vesicles, ampullae, prostate). The penis was visually assessed while erect during electro-ejaculation. Where bulls failed to achieve an erection, the penis was assessed by manual reflection of the prepuce over the penis followed by palpation and visualization performed from the side of the bull during electro-ejaculation. Leg scores, testicular tones, and BCS were all assessed according to the ACV guidelines (Beggs et al., 2013). Leg score was determined by assessing the straightness of the hind legs from a lateral viewpoint, and scored 1 to $5(1=$ pronounced sickle hocks; $2=$ moderate sickle hocks; 3 $=$ normal; $4=$ moderate post leg; $5=$ pronounced post leg).

Any abnormality involving the feet, legs, or conformation resulted in a low risk or qualified for physical classification unless it affected gait, in which case the classification became high risk. Any lame bull was classified as high risk for physical. Any abnormality of the head only resulted in a high risk classification for physical if it affected vision. Any abnormalities of the testes or internal genitalia were classified low risk or qualified for physical, with the expectation that the crush-side semen and sperm morphology categories would be high risk if the abnormality actually adversely affected semen quality. Mild penile abnormalities, such as mild balanoposthitis or small fibropapillomas without secondary complications, were classified as qualified for physical, as they would be unlikely to affect the ability of the bull to serve but would be important to monitor for possible deterioration. Moderate to severe balanoposthitis, penile or preputial injuries (including traumatized or infected fibropapillomas), or congenital deformities, such as a persistent frenulum, were classified as high risk for physical. Bulls with multiple physical abnormalities were classified according to their highest risk abnormality. Classifications given for each specific abnormality are reported in the Results and Discussion section.

Serving Ability Assessment. Serving ability assessments were not conducted due to unsuitable facilities, welfare concerns, and the ease with which herd managers were able to monitor their bulls daily once they commence work.

Table 1. Component classifications of a bull breeding soundness evaluation [modified from Australian Cattle Veterinarians (ACV) (Beggs et al., 2013)]

\begin{tabular}{ll}
\hline Classification & Definition \\
\hline Low risk & $\begin{array}{l}\text { All attributes for this component measured were consistent with the ACV standards. No risk factors for reduced fertility } \\
\text { were identified during this part of the bull breeding soundness examination. }\end{array}$ \\
Qualified & $\begin{array}{l}\text { Not all attributes for this component were consistent with ACV standards, but these abnormalities may not necessarily } \\
\text { preclude the use of the bull. }\end{array}$ \\
High risk & $\begin{array}{l}\text { Some attributes for this component measured were not consistent with ACV standards. This bull has a significant risk of } \\
\text { reduced fertility in the short term at least. }\end{array}$ \\
\hline
\end{tabular}


Crush-Side Semen Assessment. Semen was collected using an electro-ejaculator (Lane Manufacturing Inc., Denver, CO). All materials that came into contact with the semen were prewarmed $\left(37^{\circ} \mathrm{C}\right)$, and a heated microscope stage $\left(37^{\circ} \mathrm{C}\right)$ was used. The microscope used for the assessments was enclosed inside the canopy of a vehicle for herds with outdoor facilities and on a bench indoors for herds with indoor facilities. All assessments were performed by a single assessor, trained in semen handling and evaluation. After a sample was preserved in buffered formal saline for morphological assessment, a drop was placed on a microscope slide with a drop of $0.9 \%$ saline diluent, and a coverslip was placed on top; the slide was then assessed at $100 \times$ magnification (Olympus CX22, Tokyo, Japan) for progressive motility as per the ACV guidelines (Beggs et al., 2013). Bulls with $30 \%$ or more progressively motile sperm were classified as low risk, and all bulls below $30 \%$ were classified as high risk.

Sperm Morphology. Sperm samples, fixed in buffered formal saline, were assessed using a wet mount method and counted under a $100 \times$ oil immersion objective using differential-interference phase contrast microscopy (Leitz, Wetzlar, Germany) by a commercial laboratory (Chenovet, Wagga Wagga, Australia). One hundred sperm were counted and bulls with $70 \%$ or more normal sperm were classified as low risk, bulls with 50 to $69 \%$ normal sperm were classified as qualified, and bulls with less than $50 \%$ normal sperm were classified as high risk. Any bull with $20 \%$ or greater abnormal sperm categorized as proximal cytoplasmic droplets, pyriform heads, or vacuoles/teratoid was classified as high risk without regard to the overall percentage of normal sperm in the sample. Any bull with $30 \%$ or greater abnormal sperm categorized as midpiece abnormalities, loose heads or abnormal tails, knobbed acrosomes, or swollen acrosomes was classified as high risk without regard to the overall percentage of normal sperm in the sample (Beggs et al., 2013).

All results from the BBSE performed were entered into the Bull Reporter (ACV, Eight Mile Plains, Australia) software designed specifically for the purpose of recording and reporting the results of BBSE. For each visit, a report was generated using Bull Reporter and given to the herd manager.

\section{Management Questionnaires}

At the time of the premating BBSE visit, a questionnaire was administered to the participating herd manager to describe details of bull management before the mating period. This included the period from purchase or birth until the day they were evaluated. This first interview also included general questions regarding the herd itself. A sheet for recording bull removals during the mating was given to the herd manager at the first visit. At the time of the postmating BBSE visit, a second questionnaire was administered to the herd manager to describe the management of the bulls evaluated during the mating period. The questionnaire consisted of general questions about the herd, questions related to the management of bulls from rearing or purchasing up to the mating period (Table 2), questions related to bull health and biosecurity (Table 3), and questions related to the management of bulls during mating (Table 4). At the premating visit, herd managers were given a form to record the date of and reason for bull removals, as well as the fate of the bulls that were removed. A bull removal was defined as having occurred when the herd manager deemed that the bull was unsuitable for ongoing use and removed from the mating group for a period.

\section{Mating Ratios}

The current industry recommendations for mating ratios are calculated by dividing the number of bulls in the entire bull team (including those being used and those being rested) by the number of cows intended to be included in the mating period at the start of AI (InCalf, 2008). As not all herds have adequate mating records and early gestation pregnancy testing data, it is not possible for managers of these herds to know how many cows are nonpregnant at the end of the AI period. Therefore, it is not possible to make general recommendations of mating ratios based on the number of empty cows at the start of the bull mating period. To attempt to replicate industry recommendations and estimate mating ratios following the AI period, we calculated 4 mating ratios for each herd (mating ratios are expressed as percentages in the results):

1. The mating ratio expected to be used at the start of the AI period was the number of bulls the herd manager expected to have in the entire bull team divided by the total number of cows to be mated in that mating period (AI and natural matings).

2. The mating ratio actually used at the start of the AI period was the number of bulls the herd manager actually had in the entire bull team divided by the total number of cows to be mated in that mating period (AI and natural matings).

3. The mating ratio expected to be used at the start of the bull mating period was the number of bulls the herd manager expected to have in the entire bull team divided by the total number 
Table 2. Herd manager responses to questions related to rearing, grouping, and premating management of bulls

\begin{tabular}{lr}
\hline Question & No. $^{1}(\%)$ \\
\hline The age range of the bull team & $18(56)$ \\
All bulls were between 15 mo and 4 yr old & $12(38)$ \\
All bulls were $>4$ yr old & $2(6)$ \\
Bulls of both age categories were used & $16(50)$ \\
The bull team had & $16(50)$ \\
3 or more age groups & $13(41)$ \\
1 or 2 age groups & $3(9)$ \\
Rearing or purchasing practices & $5(16)$ \\
Only used purchased virgin bulls & $11(34)$ \\
Used a combination of purchased virgin and purchased experienced bulls & $30(94)$ \\
Only used bulls reared on farm & $2(6)$ \\
Used a combination of purchased and reared bulls & $11(34)$ \\
Bulls were grouped together in the bull team & $21(66)$ \\
2 mo or more before mating & $18(95)$ \\
Less than 2 mo before mating & $6(23)$ \\
When not in use in the premating period, bulls were visually inspected & $4(13)$ \\
At least weekly & \\
Less than once per week & $3(9)$ \\
Bulls were fed concentrate feed & $25(78)$ \\
From weaning to 1 yr old (19 applicable herds $\left.{ }^{2}\right)$ & $4(13)$ \\
From $>1$ to 2 yr old $\left(26\right.$ applicable herds $\left.{ }^{2}\right)$ & \\
From >2 yr old (all herds) & \\
In the 3 mo before mating, bulls were fed & \\
Pasture only & \\
Pasture and hay or silage & \\
Pasture, hay or silage, and concentrates & \\
${ }^{1} \mathrm{n}=32$ herds unless otherwise stated. & \\
${ }^{2}$ Applicable herds were herds that reared bulls and therefore managed bulls in these age groups. &
\end{tabular}

of cows remaining empty at the end of the AI period, estimated from pregnancy testing data.

4. The mating ratio actually used at the start of the bull mating period was the number of bulls the herd manager actually had in the entire bull team divided by the total number of cows remaining empty at the end of the AI period, estimated from pregnancy testing data.

The expected and actual numbers of bulls in the entire bull team were determined by asking the herd manager at the pre- and postmating BBSE visits, respectively. The entire bull team included all bulls used for natural service with the milking herd for that mating period, regardless of how many were being used or rested at any one time. Pregnancy testing via rectal palpation or rectal ultrasound was performed at various intervals following the end of the AI period (6 to $30 \mathrm{wk}$ ), meaning that the numbers of nonpregnant cows following $\mathrm{AI}$ are crude estimates only, as the accuracy of estimated stages of pregnancy from pregnancy diagnosis decreases as gestation progresses.

\section{RESULTS AND DISCUSSION}

\section{Animals and Herds}

Of the 32 herds included in the study, 17 (53.1\%) were seasonally calving and $15(46.9 \%)$ were split-calving herds. The mean herd size (milking cows) was 425

Table 3. Herd manager responses to questions related to bull health and biosecurity

\begin{tabular}{lr}
\hline Question & No. $(\%)$ \\
\hline In the previous 12 mo bulls had been & $26(81)$ \\
Treated with an anthelmintic & $9(28)$ \\
Vaccinated with 5 in 1 (clostridial spp.) or 7 in 1 (clostridial + leptospiral spp.) & $25(78)$ \\
Vaccinated for campylobacteriosis & $2(6)$ \\
Vaccinated for BVDV & $1(3)$ \\
Bulls are routinely tested for BVDV antigen status & $3(9)$ \\
Supplementary vitamins and minerals are administered to bulls & $13(41)$ \\
Purchased bulls are quarantined for a period of time & $14(44)$ \\
Bulls are shared with other herds &
\end{tabular}

${ }^{1} \mathrm{BVDV}=$ bovine viral diarrhea virus. 
Table 4. Herd manager responses to questions related to management of bulls during study mating period

\begin{tabular}{|c|c|}
\hline Question & No. $^{1}(\%)$ \\
\hline \multicolumn{2}{|l|}{ At any given time during mating } \\
\hline Only one bull was being used & $3(9)$ \\
\hline More than one bull was being used & $29(91)$ \\
\hline Bulls were rotated (had a period of rest) during mating period & $28(88)$ \\
\hline \multicolumn{2}{|l|}{ If bulls were rotated $(n=28)$, they were rotated } \\
\hline As individual bulls & $5(18)$ \\
\hline In groups & $23(82)$ \\
\hline \multicolumn{2}{|l|}{ The bull team was } \\
\hline Observed regularly and bulls incapable of service were removed & $24(75)$ \\
\hline Observed regularly and incapable bulls were not removed & $5(16)$ \\
\hline Not observed regularly & $3(9)$ \\
\hline Bulls were observed while actually mating & $28(88)$ \\
\hline \multicolumn{2}{|l|}{ If bulls were observed while actually mating $(\mathrm{n}=28)$, this was done } \\
\hline Daily & $15(54)$ \\
\hline Every $2-3 \mathrm{~d}$ & $11(39)$ \\
\hline Weekly & $2(7)$ \\
\hline \multicolumn{2}{|l|}{ Bulls were assessed for lameness or injuries } \\
\hline Daily & $28(88)$ \\
\hline Every $2-3 \mathrm{~d}$ & $2(6)$ \\
\hline Weekly & $2(6)$ \\
\hline \multicolumn{2}{|l|}{ During mating, bulls were fed } \\
\hline Pasture only & $12(38)$ \\
\hline Pasture and hay or silage & $14(44)$ \\
\hline Pasture, hay or silage, and concentrates & $6(19)$ \\
\hline \multicolumn{2}{|l|}{ When herd managers identified a lame bull $(\mathrm{n}=23)$, the bull was } \\
\hline Replaced immediately & $18(78)$ \\
\hline Replaced only if he did not improve in a few days & $3(13)$ \\
\hline Left with the herd & $2(9)$ \\
\hline \multicolumn{2}{|l|}{ Bulls } \\
\hline Stood or walked on concrete yards & $32(100)$ \\
\hline Stood or walked on tracks & $32(100)$ \\
\hline Were chased by dogs & $4(13)$ \\
\hline \multicolumn{2}{|l|}{ At milking times } \\
\hline Bulls were separated from the herd on the dairy track & $2(6)$ \\
\hline Bulls were separated from the herd in the dairy yard & $25(78)$ \\
\hline Bulls were not separated from the herd and went through the dairy & $5(16)$ \\
\hline \multicolumn{2}{|l|}{ At the end of mating, lame or injured bulls } \\
\hline Are always culled & $5(16)$ \\
\hline Are sometimes culled & $22(69)$ \\
\hline Are never culled, and always allowed time to improve before next mating & $5(16)$ \\
\hline
\end{tabular}

${ }^{1} \mathrm{n}=32$ herds unless otherwise stated.

(range $=154-910)$, and the mean number of cows to be mated in the mating period was 328 (range $=100-825$ ). The number of bulls evaluated at the premating visit was 256 . Of the 256 bulls, 200 were present and eligible for evaluation at the postmating visit. Time from bull evaluation to the start of the bull mating period ranged from 0 to $82 \mathrm{~d}$ (mean $=27 \mathrm{~d})$. Following the mating period, bulls were re-evaluated between 0 and $13 \mathrm{~d}$ (mean $1.5 \mathrm{~d}$ ) after the bull mating end date. Fifty-six bulls were not evaluated again at the postmating visit.

Of the 256 bulls included in the premating BBSE, 154 $(60.2 \%)$ had been purchased off-farm and $102(39.8 \%)$ had been reared on-farm, $70(27.3 \%)$ were virgin bulls and $186(72.7 \%)$ had been used before. The breed distribution of the bulls premating was 171 Holstein (66.8\%), 54 Jersey (21.1\%), and 31 other (Angus, Murray Grey, Swedish Red, Aussie Red, Guernsey, Hereford, Shorthorn, Ayrshire, Jersey $\times$ Holstein; 12.1\%). The breed distribution of the bulls postmating was 138 Holstein (69.0\%), 37 Jersey (18.5\%), 25 other (Angus, Murray Grey, Swedish Red, Aussie Red, Guernsey, Hereford, Shorthorn, Ayrshire, Jersey $\times$ Holstein; 12.5\%). At the premating BBSE the bulls used ranged in age from 1.2 to $8.2 \mathrm{yr}$ old $($ mean $=3.2 \mathrm{yr}$ old $)$.

\section{Management Questionnaires}

Responses from the questionnaire performed at the premating visit, which relate to the premating, health, and biosecurity management of the bulls used, are displayed in Tables 2 and 3. The mean length of the AI period was $56 \mathrm{~d}$ (range $=20-111$ ) and the mean length of the following bull mating period was $58 \mathrm{~d}$ (range $=$ 17-132); the mean number of bulls the herd managers expected to use was 8.1 (range $=3-19$ ), whereas the mean number of bulls actually used was 7.3 (range $=$ 
$3-16)$. The mean mating ratio expected to be used at the start of AI was $2.7 \%$ (i.e., 2.7 bulls in the entire bull team per 100 cows to be mated; range $=1.1-6.1$ ) and the mean mating ratio actually used at the start of AI was $2.5 \%$ (range $=1.2-5.2$ ). The mean mating ratio expected to be used at the start of the bull mating period was $8.3 \%$ (i.e., 8.3 bulls in the entire bull team per 100 empty cows remaining at the end of the AI period; range $=3.3-19.7)$ and the mean mating ratio actually used at the start of the bull mating period was $6.4 \%$ (range $=2.3-14.2$ ). The mean longest cow track (longest distance to walk from dairy to grazing paddock) on the study farms was $2.0 \mathrm{~km}$ (range $=1-5$ ), and during lactation the mean daily walk for the herd was $2.8 \mathrm{~km}$ (range $=0.5-5.0$ ). During the mating period, bulls were used for a mean of $6.2 \mathrm{~d}$ (range $=1-14$ ) before being rested, and were rested for a mean of 7.0 $\mathrm{d}$ (range $=1-14$ ) before being reused. Table 4 displays the responses to questions asked at the postmating BBSE, which relate to the management of the bulls during the mating period.

Industry information indicates that natural service is commonly used in Australia and identifies a gap of knowledge relating to dairy herd bull management (Woolaston and Shephard, 2011). Given the typical 6 -wk in-calf rates of $50 \%$ that have been reported in Australian herds (Dairy Australia, 2011) and assuming an AI period of $8 \mathrm{wk}$, in a typical Australian dairy herd it would be reasonable to estimate that about 30 to $40 \%$ of the herd would not conceive to AI and be presented to the herd bulls for mating. For this reason, it is surprising to find such a lack of research into dairy herd bull management, both in Australia and internationally. Due to this lack of activity, we have no findings to compare our results to in the subsequent discussion. This lack of activity in the research field is reflected in practice, with only 1 of the 32 herds in our study having ever previously had their bulls undergo a BBSE. In our experience, the strategy of herd managers in our region is not to use a BBSE and instead simply use more bulls than they perceived were required, when, in fact, our herds actually used fewer bulls than they expected. Several studies have demonstrated that in multiple-sire matings a minority of the bulls sire most the calves (Osterhoff, 1966; Lehrer et al., 1977; Holroyd et al., 2002). If a dominant bull is subfertile and prevents fertile subordinate bulls from mating, then herd fertility may be adversely affected (Petherick, 2005). Another potential consequence of using high mating ratios is an increased risk of injuries associated with betweenbull aggression (Fordyce et al., 2002). We believe the health and soundness of herd bulls should receive more emphasis, with a shift in attitude toward dairy herds using better bulls, not just more bulls.
The recommendation of the national dairy advisory body to herd managers is that bulls have intermittent periods of rest from service (InCalf, 2008), a practice referred to as rotation. The proportion of herds that employed a rotation policy would suggest that these recommendations have been widely followed. To our knowledge, no one has proven the importance of rotation of herd bulls in maintaining a fertile bull team. Social hierarchy changes due to the rotation of bulls could actually increase the risk of injuries and lameness during the mating period (Petherick, 2005). Further research in this area would seem suitable to provide an evidence base for solid recommendations on bull rotation and mating ratios. Another important management role during mating is the observation of bulls to assess their willingness and ability to mate as well as lameness and injuries. The majority of herd managers in our study reported regularly observing their bulls; however, in herds where matings were observed only half of these herd managers observed mating on a daily basis whereas nearly all monitored for lameness and injuries daily. These findings suggest that herd managers are good at regular assessment for lameness but may not be as efficient in assessing serving ability. Herd managers should be trained not just to be vigilant in assessing lameness, but also to ensure that bulls are observed mating daily and are capable of performing natural service.

Campylobacteriosis vaccination and anthelmintic treatments were broadly implemented, whereas regular clostridial (with or without leptospiral) vaccination and bovine viral diarrhea virus control and screening measures were not (Table 3). Biosecurity measures in our study herds appeared to be poor, with nearly half of all herds sharing bulls with other herds, deliberately or otherwise, and nearly half not quarantining bulls when they arrived on property (Table 3 ). Preventative health and biosecurity measures for bulls could be improved by providing a more standardized protocol.

Most of the reared bulls in our study were fed supplementary concentrates as calves (up to $12 \mathrm{mo}$ ). The proportion of bulls fed concentrates declined markedly after 12 mo of age and further still as mature bulls. The bulls fed concentrate during mating were probably receiving a lactating cow ration in the dairy. The effect of nutrition on the BBSE results in our study is discussed in more detail elsewhere (Hancock et al., 2016).

One quarter of herd managers culled bulls if they were too big for the cows. The remainder culled their bulls at a mean age of $4.7 \mathrm{yr}$ (range $=2.5-7.0)$. In some herds, bulls were also culled due to bad temperament and severe injury. If a bull was lame or injured at the end of the mating period, only a small proportion of herd managers would definitely cull that bull, whereas 


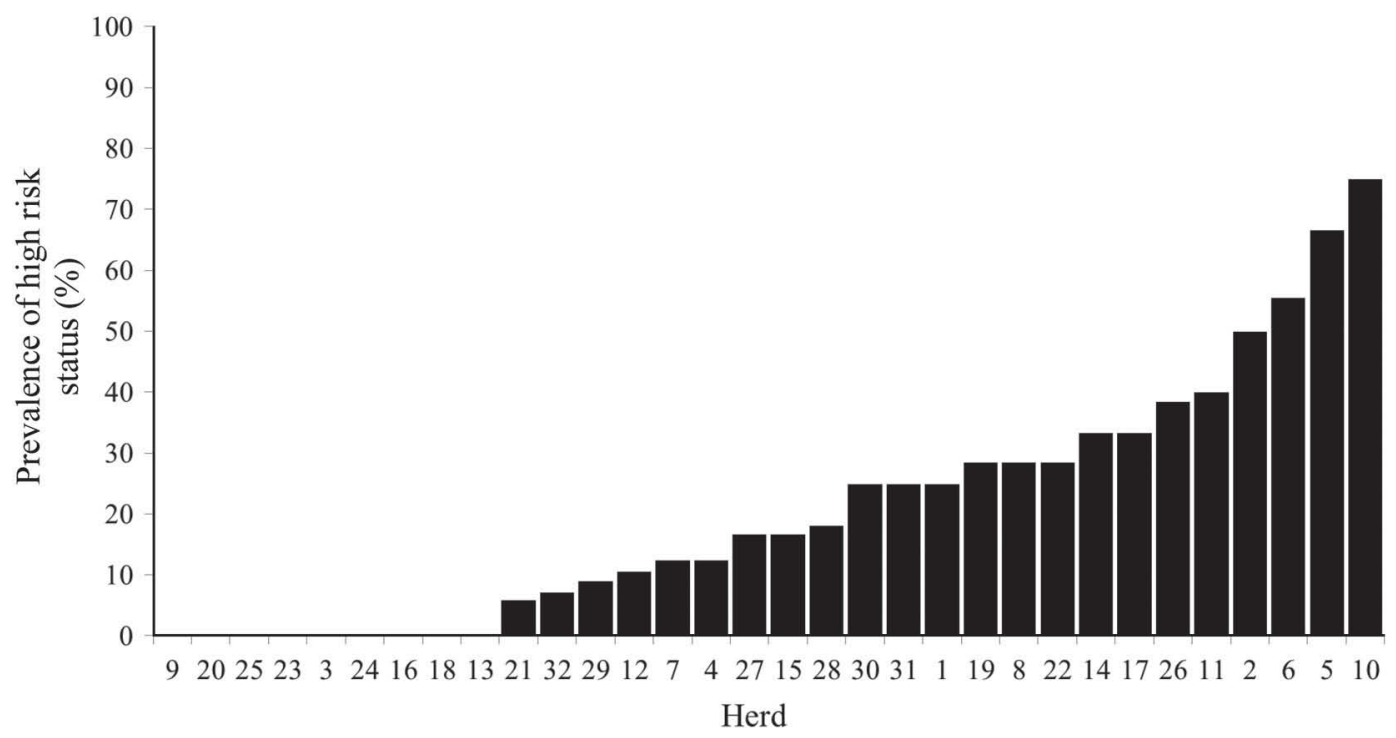

Figure 1. Herd-level prevalence of bulls classified as being at high risk of reduced fertility at a premating bull breeding soundness evaluation of dairy herd bulls in southern Australia.

most herds would allow the bull time to recover before the next mating. These practices may be a risk factor for bulls carrying chronic injuries into subsequent mating periods, and may help explain the prevalence of high risk status premating.

\section{BBSE}

Overall Classifications and Physical Component. The classifications for each component of the BBSE, as well as the overall classifications given to each bull are summarized in Table 5. Some bulls received qualified or high-risk classifications for more than 1 component of the BBSE. The pre- and postmating prevalence by herd are displayed in Figures 1 and 2 , respectively. The figures show a wide range of prevalence of high-risk bulls before and after the mating period. As this within-herd prevalence increases, it would be expected that the likelihood that dominant bulls are also high risk would as well, assuming that, regardless of social hierarchy, all bulls in that herd have the same probability of being classified as high risk.

The findings of the physical component of the BBSE are displayed in Table 6 . Any bull that showed evidence of lameness was designated as abnormal for gait and classified as high risk for physical. Of the 19 lame bulls premating, 16 were lame on 1 or both of the back legs and 3 were lame on a front leg. Of the 49 lame bulls postmating, 39 were lame on 1 or both of the back legs, 9 were lame on one or both of the front legs, and 1 was lame in all 4 legs. Any bull with 1 or more leg joints with visible or palpable swelling was graded abnormal for joints. Of those graded as abnormal in either visit, almost all had swelling in the hock joints, with only 1 bull having swollen stifle joints (abnormal pre- and postmating), and 1 had a swollen carpus (premating, not assessed postmating). Joint swelling ranged in severity from mild to severe and resulted in a classification of qualified unless the bull was also lame or the swelling was severe, in which case a high-risk clas-

Table 5. Component and overall classifications for the pre- and postmating bull breeding soundness evaluations (BBSE) ${ }^{1}$

\begin{tabular}{|c|c|c|c|c|c|c|c|c|c|c|c|c|}
\hline BBSE component & \multicolumn{6}{|c|}{ Premating } & \multicolumn{6}{|c|}{ Postmating } \\
\hline Physical & 187 & 73.1 & 40 & 15.6 & 29 & 11.3 & 94 & 47.0 & 44 & 22.0 & 62 & 31.0 \\
\hline Crush-side semen & 243 & 95.7 & 3 & 1.2 & 8 & 3.2 & 181 & 96.8 & 0 & 0.0 & 6 & 3.2 \\
\hline Sperm morphology & 224 & 88.2 & 8 & 3.2 & 22 & 8.7 & 169 & 90.4 & 7 & 3.7 & 11 & 5.9 \\
\hline
\end{tabular}

${ }^{1} \mathrm{n}=256$ premating; $\mathrm{n}=200$ postmating. 
sification was applied. Of the 36 bulls with abnormalities in the feet premating, 27 had abnormally shaped claws (scissor claw or corkscrew claw), 5 had overgrown claws, 3 had horizontal fissures, and 1 had a cut on the heel bulb. Of the 25 bulls with abnormalities in the feet postmating, 20 had abnormally shaped claws (scissor claw or corkscrew claw), 4 had overgrown claws, and 1 had horizontal fissures. Bulls with abnormally shaped or overgrown claws were classified as low risk unless the abnormality was severe, and bulls with fissures or cuts were classified as qualified. Head abnormalities included keratoconjunctivitis lesions (active and scar tissue), bony swellings, eyelid cancers, and mucopurulent nasal and ocular discharge. Active keratoconjunctivitis lesions and third eyelid cancers received a qualified classification for physical, the rest were classified as low risk.

Physical abnormalities of the penis made up the majority of the abnormalities of the reproductive organs. Premating 15 bulls had balanoposthitis, 6 had penile fibropapillomas, 2 had penile-preputial adhesions, 1 had a preputial abscess, 1 had a persistent frenulum, and 1 had ulcerated, fibrotic lesions on the distal penis (Figure 3). Postmating 24 bulls had resolving ulcerating scar tissue lesions on the glans penis, 14 had balanoposthitis, 6 had penile fibropapillomas, 3 had penile-preputial adhesions, and 1 had a preputial abscess. Testicular abnormalities included asymmetrical, misshapen, or cleft testes (premating $=10$; postmating $=6$ ), severe unilateral testicular degeneration (premating $=1$ ), orchitis (premating $=1$ ), and abdominal cryptorchid (premating $=1$ ). The first of these testicular abnor- malities were classified as low risk for physical and the remaining 3 were classified as high risk. Scrotal abnormalities included dry and thickened scrotal skin, scars (both low risk), and mild photosensitization (qualified). Finally, seminal vesicular and epididymal abnormalities were composed of seminal vesiculitis (qualified) and unilateral enlargement of the epididymis (low risk), respectively. No bulls (pre- or postmating) were classified as qualified for physical as a result of not meeting the age-based minimum required threshold for scrotal circumference.

Our observed premating prevalence of high-risk status, $19.5 \%$, fits in to the observed range seen in studies of beef bulls, where 6 to $33 \%$ of bulls were classified as high risk or unsatisfactory (Elmore et al., 1975; Bruner et al., 1995; Acuña and Campero, 1999; Chacón et al., 1999; Kennedy, 2002; Waldner et al., 2010; Menegassi et al., 2012). Those studies came from widely varied geographical locations and farming systems, with differences in the guidelines used for classification of breeding soundness. No peer-reviewed studies exist for comparison of our results in dairy herd bulls. However, it is apparent that in any population of bulls a certain proportion of bulls will be unsatisfactory, emphasizing the need to assess bulls before they are used regardless of the farming system.

As the serving ability component of the BBSE was not performed in our study, it is likely that the premating prevalence of high-risk status would have been even higher had it been undertaken. In one study, 3 to $5 \%$ of bulls were rejected based on serving capacity test (Menegassi et al., 2012). McDiarmid (1981) reported

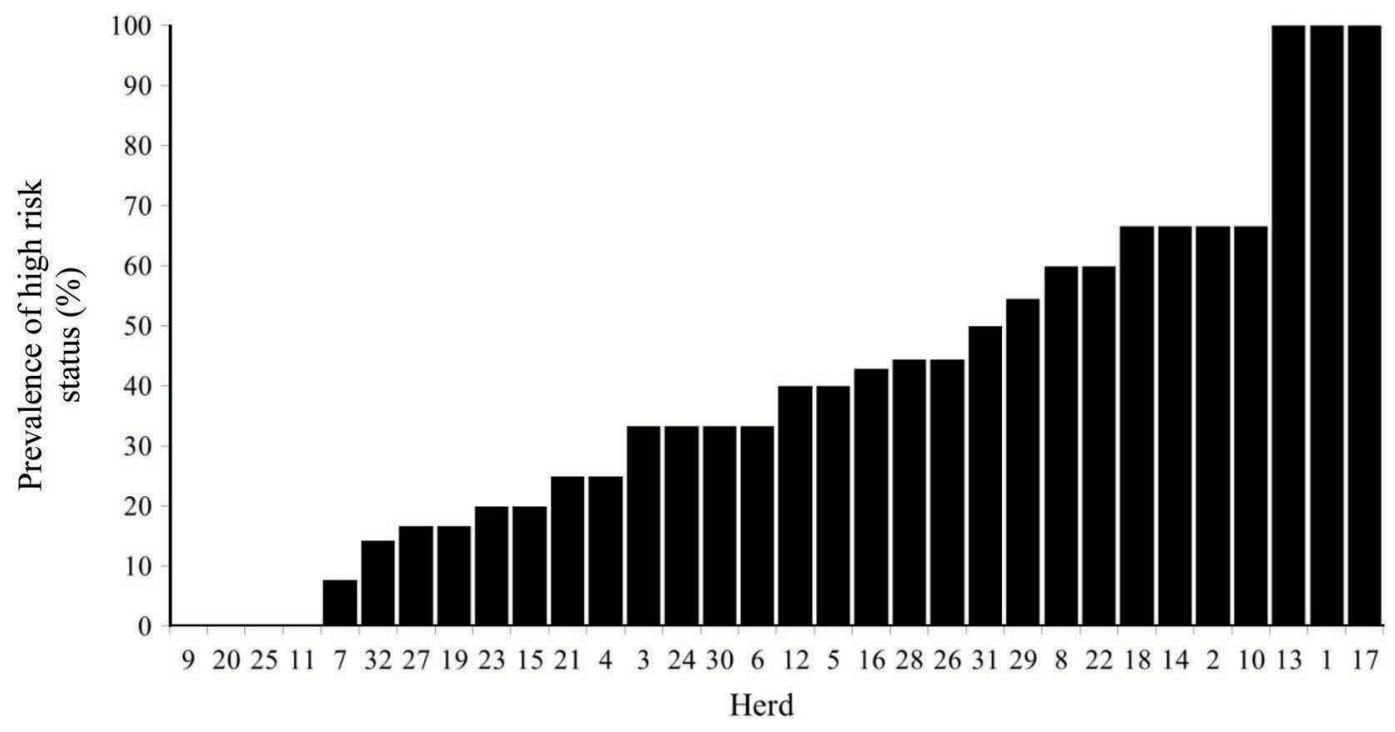

Figure 2. Herd-level prevalence of bulls classified as being at high risk of reduced fertility at a postmating bull breeding soundness evaluation of dairy herd bulls in southern Australia. 
Table 6. Descriptive statistics of physical variables of the premating and postmating bull breeding soundness evaluations

\begin{tabular}{|c|c|c|c|c|c|c|c|c|}
\hline \multirow[b]{2}{*}{ Variable } & \multirow[b]{2}{*}{$\mathrm{n}$} & \multirow[b]{2}{*}{$\begin{array}{l}\text { Mean } \\
(\mathrm{SD})\end{array}$} & \multirow[b]{2}{*}{$\begin{array}{c}\text { Median } \\
\text { (quartile 1, 3) }\end{array}$} & \multirow[b]{2}{*}{$\begin{array}{l}\text { Minimum, } \\
\text { maximum }\end{array}$} & \multicolumn{2}{|c|}{ Premating $(\mathrm{n}=256)$} & \multicolumn{2}{|c|}{ Postmating $(\mathrm{n}=200)$} \\
\hline & & & & & $\begin{array}{c}\text { No. } \\
\text { abnormal }\end{array}$ & $\begin{array}{l}\text { Bulls } \\
\text { affected } \\
(\%)\end{array}$ & $\begin{array}{c}\text { No. } \\
\text { abnormal }\end{array}$ & $\begin{array}{c}\text { Bulls } \\
\text { affected } \\
(\%)\end{array}$ \\
\hline \multicolumn{9}{|l|}{ Premating } \\
\hline $\mathrm{BCS}^{1}$ & 256 & $3.3(0.5)$ & $3.5(3.0,3.5)$ & $2.5,4.5$ & & & & \\
\hline Leg score ${ }^{2}$ & 256 & & $3.0(3.0,4.0)$ & $3.0,5.0$ & & & & \\
\hline Scrotal circumference $(\mathrm{cm})$ & 256 & $39.0(3.0)$ & $39.0(37.0,41.0)$ & $32.0,47.5$ & & & & \\
\hline Testicular tone $^{2}$ & 256 & & $3.0(2.0,3.0)$ & $2.0,4.0$ & & & & \\
\hline \multicolumn{9}{|l|}{ Postmating } \\
\hline BCS & 200 & $3.3(0.5)$ & $3.5(3.0,3.5)$ & $2.0,4.5$ & & & & \\
\hline Scrotal circumference $(\mathrm{cm})$ & 200 & $39.2(2.7)$ & $39.0(37.5,41.0)$ & $33.0,48.5$ & & & & \\
\hline Testicular tone ${ }^{2}$ & 200 & & $3.0(2.0,3.0)$ & $1.0,4.0$ & & & & \\
\hline \multicolumn{9}{|l|}{ Locomotor vision } \\
\hline Gait & & & & & 19 & 7.4 & 49 & 24.5 \\
\hline Joints & & & & & 30 & 11.7 & 43 & 21.5 \\
\hline Feet & & & & & 36 & 14.1 & 25 & 12.5 \\
\hline Head & & & & & 7 & 2.7 & 4 & 2.0 \\
\hline \multicolumn{9}{|l|}{ Reproductive } \\
\hline Penis & & & & & 26 & 10.2 & 48 & 24.0 \\
\hline Testes & & & & & 13 & 5.1 & 5 & 2.5 \\
\hline Scrotum & & & & & 7 & 2.7 & 1 & 0.5 \\
\hline Seminal vesicles & & & & & 6 & 2.3 & 3 & 1.5 \\
\hline Epididymis & & & & & 4 & 1.6 & 3 & 1.5 \\
\hline
\end{tabular}

${ }^{1}$ The ordinal variable BCS was assumed to be continuous.

${ }^{2}$ Scored on a scale of 1 to 5 .

that $15 \%$ of bulls were poor performers in a serving capacity test due to spiral deviation (46\%), flaccid or injured penises $(10 \%)$, locomotor system abnormalities (10\%), and low serving capacity (34\%). Spiral deviation of the penis alone has been reported at a range of 7 (McDiarmid, 1981) to 10\% (Blockey and Taylor, 1984)

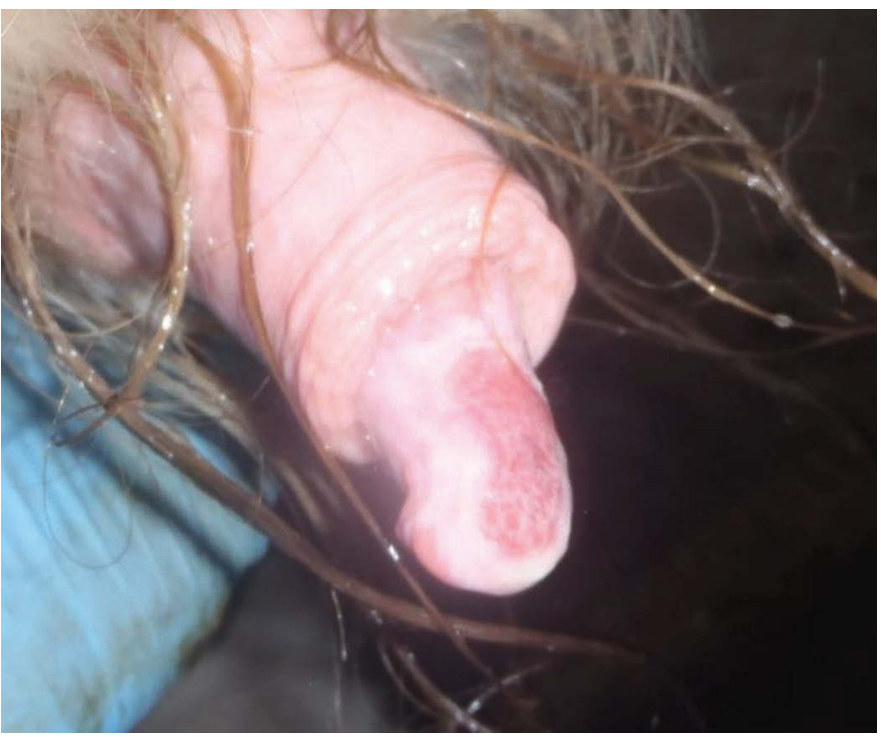

Figure 3. Lesion on distal glans penis seen at a postmating bull breeding soundness evaluation of a dairy herd bull in southern Australia. Color version available online. of bulls, a defect that can only be diagnosed in the serving ability component of a BBSE. It is important in dairy herds that perform a routine premating BBSE without this component for herd managers monitor their bulls during use to assess libido as well as ability to achieve normal erection and intromission (Bertram et al., 2002). Dairy herd managers in our system have an advantage over beef herd managers in that they have the opportunity to observe their bulls twice daily when the herd is yarded for milking. This allows for easy observation and probably reduces the need for a serving test, provided that herd managers are well educated on what abnormalities they are looking for.

In the study herds, the high-risk bulls identified premating were to be used in the normal course of events in the upcoming natural mating period. Almost half of the high-risk bulls were classified as such because of abnormal semen traits, and the other half due to physical defects made up of lameness and penile and testicular abnormalities. Therefore, a large proportion of these high-risk bulls would only have been detected by performing a premating BBSE. Although debate exists regarding the accuracy of the BBSE as a predictor of fertility (Kastelic and Thundathil, 2008), there is a high likelihood that a bull with penile adhesions, a persistent frenulum, or marked testicular degeneration (as examples of physical defects seen in the study) will have a marked reduction in fertility. Most of these abnormalities will only be detected in dairy herds using 
the BBSE premating as a risk-management tool, which emphasizes the importance of the BBSE as an identifier of poor fertility bulls. Adequate evidence exists that sperm morphology assessment is a good predictor of fertility in bulls (Coulter and Kozub, 1989; Holroyd et al., 2002; Al-Makhzoomi et al., 2008), and is a risk factor measured by BBSE. Thus, dairy herd bulls should undergo a BBSE before mating, which has already been a long-standing recommendation in the Australian beef industry (Fitzpatrick et al., 2002; McGowan et al., 2002).

In regard to other studies that have performed a postmating BBSE, most of them only used small numbers of bulls with short mating periods (up to $4 \mathrm{~d}$ ) in small mating groups to assess libido, serving capacity, and other behavioral traits (Smith et al., 1981; Boyd et al., 1989; Godfrey and Lunstra, 1989). None of these studies revealed any major changes from pre- to postmating BBSE, but due to the major design differences, these findings are of minor relevance when discussing the bulls in our study. In a study with a longer mating period (44 d), bulls lost 30 to $32 \mathrm{~kg}$ of $\mathrm{BW}$, on average, over the breeding period but otherwise failed to demonstrate any major changes in BBSE characteristics from pre- to postmating (Boyd et al., 1991). The bulls in our study maintained body condition on average over the mating period. This may be due to mating bulls being fed the same forage ration as the herd (as well as a concentrate ration in some herds), which is usually high in quality and quantity to maximize milk production. The effects of mating ratios and rotation policies on workload may have also influenced this result.

In beef bulls, a comparable study to ours was performed by Ellis et al. (2005). In their study, bulls were joined in multiple-sire groups over a 63 -d mating period at a mating ratio of approximately $5 \%$. At the postmating BBSE, $36.8 \%$ of bulls were classified as unsatisfactory and had very high incidences of lameness (63\%) and injuries $(75 \%)$ throughout the mating period. Those authors also observed substantial decreases in BW, BCS, and morphologically normal sperm over the mating period. It was proposed that the sexual inexperience of yearling bulls made an important contribution, resulting in mating injuries due to over-aggressive sexual and social behavior, which may have been exacerbated by the high mating ratio used in the study (Fordyce et al., 2002). Although not published in a peer-reviewed journal, a case study reported at a dairy management conference discussed problems seen during mating in dairy herd bulls (Chenoweth et al., 2003). These bulls were kept in concrete freestalls with some access to dirt lots and were used for natural service in a 2,500-cow dairy. Lameness was reported in $23 \%$ of the 98 bulls after they had been used for mating. Those authors' proposed causal factors for the lameness were trauma due to fighting and loss of footing on concrete, as well as nutritional factors (feeding a lactating cow ration) leading to laminitis and possibly bony lesions in the leg joints and spines due to excessive energy and calcium levels.

Lame bulls made up approximately two-thirds of the bulls classified as high risk at the postmating BBSE, making lameness the biggest cause of postmating high-risk classification. Lameness is a major problem in pasture-based dairy cows. In studies involving Australian and New Zealand pasture-based dairy cows the individual herd incidence (annual or lactational) of lameness ranged from 0 to $38 \%$, with reported average incidence risks of $2.5 \%$ annually, $16 \%$ annually, and $7.5 \%$ per lactation (Harris et al., 1988; Jubb and Malmo, 1991; Tranter and Morris, 1991, respectively). Foot lesions made up 91 to $98 \%$ of all cases of lameness (Jubb and Malmo, 1991; Tranter and Morris, 1991; Murray et al., 1996; Chesterton et al., 2008). Some of the common risk factors reported to contribute to lameness in pasture-based dairy cows included herd size, breed, age, nutrition, exercise, track condition, terrain, season, technique of herding cows on tracks, and calvingrelated changes in hoof structure (Harris et al., 1988; Chesterton et al., 1989; Tarlton et al., 2002; Westwood et al., 2003). Several of the bulls in our study may have been exposed to some of these factors. Additionally, the bulls were possibly exposed to risk factors mentioned by Ellis et al. (2005), such as sexual inexperience and fighting, and Chenoweth et al. (2003), such as spending long periods of time standing and working on concrete and being fed concentrate before and during mating. Exposure to these risk factors could explain the high prevalence of lameness seen at the postmating BBSE.

Although the effect of lameness on bull fertility has not been directly quantified, it is likely that in the circumstances in which dairy herd bulls are used, reduced mobility affects mating performance. Bulls had to walk an average of nearly $3 \mathrm{~km}$ daily in addition to serving estrous cows; thus, lame bulls probably fail to reach their expected breeding potential. We recommend that control measures be implemented to reduce lameness on pasture-based dairy herds as a way of increasing the longevity and performance of dairy herd bulls. Given the animal welfare implications of lameness, these recommendations are prudent regardless of any potential benefit to fertility.

The types of penile abnormalities and prevalence of abnormalities we observed are similar to those reported elsewhere. In 1 herd bulls were undergoing an outbreak of infectious pustular balanoposthitis premating, with 5 bulls positive for bovine herpes virus 1 (BHV-1) identified by PCR from penile swab samples. This outbreak 
accounted for nearly $20 \%$ of premating penile abnormalities. A separate, distinct lesion was also observed postmating in 24 bulls (12 herds), presenting on the distal glans penis. One bull also displayed the lesion premating, although this bull had been used to mate heifers before the premating BBSE. The lesions were located at the distal end of the glans penis and grossly appeared as mildly to moderately ulcerated lesions with surrounding fibrinous appearance and granulomatous tissue covering the ulcerated area (Figure 3). The lesions were about 1 to $3 \mathrm{~cm}$ in diameter and did not appear to be painful or infected; only 1 of the bulls with these lesions was BHV-1-positive (Hancock et al., 2015).

It is possible that these lesions were due to resolving infectious pustular balanoposthitis, and it would have been useful to have examined penises daily during mating to assess the development of lesions. If BHV-1 did cause the lesions, these bulls may not have been shedding BHV-1 by the time they were sampled. It may be that the lesions were resolving balanoposthitis lesions caused by a different pathogen, such as Ureaplasma diversum, which has been implicated as a cause of balanoposthitis in Australian beef bulls (Argue et al., 2013). If these lesions were infectious in nature, it would seem probable that some of these 24 bulls would have had lesions that appeared more actively inflamed, possibly displaying signs of secondary infections such as pustules or purulent exudate. Although bulls had active balanoposthitis postmating, these bulls tended to display more classic signs of a generalized erythema and papular or pustular lesions on the glans penis rather than the localized lesions described above. We speculated that the lesions were due to the physical wear and tear of mating.

Crush-Side Semen and Sperm Morphology Components. The results that describe the components crush-side semen and sperm morphology are in Table 7. These results are consistent with other studies with respect to motility and percent morphologically normal sperm (Al-Makhzoomi et al., 2008; Waldner et al., 2010). The most common morphological defects noted were midpiece defects, which are a commonly observed defect, although a higher proportion of bulls with sperm head defects than we observed have been reported (Barth and Waldner, 2002; Ellis et al., 2005; Al-Makhzoomi et al., 2008; Freneau et al., 2010). Interestingly, at the pre- and postmating BBSE, the lower 25th percentile for both motility and percent morphologically normal sperm in our samples fell into the low risk classification for crush-side semen and sperm morphology, meaning that an overwhelming majority of bulls in our study had semen of good quality. Also, the quality of semen did not deteriorate during the mating period, unlike the observations of Ellis et al. (2005) postmating, who suggested that the decrease was due to a combination of physiological (mostly injury related) and climatic factors. Therefore, it appears unlikely that our bulls were exposed to the same level of stress as those in the Ellis et al. (2005) study. This may be due to the lower ambient temperatures observed during our study period, or because the injuries and lameness observed in our study bulls were milder in nature, or perhaps because of less frequent exposure of our study bulls to adverse behavioral factors.

\section{Fate and Removals}

Not every bull presented for evaluation at the premating BBSE was presented again at the postmating BBSE. The 56 bulls tested premating but not postmating are accounted for in Table 8, where the final fate of the bulls is displayed. Of the 207 bulls used, herd managers recorded 33 removals during mating (15.9\% of bulls used), and the reasons for the removals are displayed in Figure 4. The mean number of days it took for a bull to be removed was $29.6 \mathrm{~d}$. Of the 33 bulls recorded as being removed, 17 were rested and reused, 9 were rested but not reused, and 7 died or were culled (and therefore not tested postmating).

In addition to being the major cause of high-risk status postmating, lameness and musculoskeletal injuries contributed to the vast majority of manager-reported bull removals during the mating period. This is not surprising, given the high numbers of lame bulls observed postmating and the fact that most herd managers in the study regularly observed their bulls and assessed them for lameness and injuries. The overall removal rate falls in the range of reported incidences for comparable studies, which describe causes of bull attrition during mating seasons of between 5 to $7 \%$ (herd manager reported; Waldner et al., 2010) and 75\% (all injuries during breeding, researcher reported; Ellis et al., 2005). A large discrepancy exists in these studies between the herd manager-reported incidence of removal and the incidence of bull failure reported by researchers observing the bulls, which is further supported by the fact that $25 \%$ of bulls were lame at the end of mating in our study yet only $16 \%$ of bulls were removed during the mating period by herd managers. This discrepancy may be explained by differing criteria used for describing bull removal and attrition. Another interpretation may be that herd managers could be missing or ignoring lame and injured bulls during mating, and a lack of early detection and removal or treatment may exacerbate the injury or lameness. 
Table 7. Semen characteristics of the pre- and postmating bull breeding soundness evaluations

\begin{tabular}{|c|c|c|c|c|}
\hline Semen characteristic (\%) & $\mathrm{n}^{1}$ & $\begin{array}{l}\text { Mean } \\
(\mathrm{SD})\end{array}$ & $\begin{array}{c}\text { Median } \\
\text { (quartile 1,3) }\end{array}$ & $\begin{array}{l}\text { Minimum, } \\
\text { maximum }\end{array}$ \\
\hline Premating & 254 & & & \\
\hline Motility & & $61(16)$ & $60(50,70)$ & 10,90 \\
\hline Normal sperm & & $82(18)$ & $87(80,91)$ & 2,97 \\
\hline \multicolumn{5}{|l|}{ Abnormal sperm } \\
\hline Midpiece defects & & $9(15)$ & $5(2,9)$ & 0,96 \\
\hline Loose heads/abnormal tails & & $3(6)$ & $2(1,3)$ & 0,56 \\
\hline Vacuoles/teratoids & & $2(3)$ & $1(0,4)$ & 0,19 \\
\hline Pyriform heads & & $2(3)$ & $1(0,3)$ & 0,19 \\
\hline Proximal droplets & & $2(4)$ & $1(0,2)$ & 0,42 \\
\hline Knobbed acrosomes & & $0.1(0.3)$ & $0(0,0)$ & 0,2 \\
\hline Swollen acrosomes & & $0.0(0.1)$ & $0(0,0)$ & 0,1 \\
\hline Postmating & 187 & & & \\
\hline Motility & & $61(16)$ & $60(50,70)$ & 0,90 \\
\hline Normal sperm & & $85(13)$ & $89(82,92)$ & 6,97 \\
\hline \multicolumn{5}{|l|}{ Abnormal sperm } \\
\hline Midpiece defects & & $7(9)$ & $4(2,8)$ & 0,57 \\
\hline Loose heads/abnormal tails & & $3(7)$ & $2(1,3)$ & 0,81 \\
\hline Vacuoles/teratoids & & $0.3(1.2)$ & $0(0,0)$ & 0,8 \\
\hline Pyriform heads & & $3(4)$ & $3(1,5)$ & 0,41 \\
\hline Proximal droplets & & $2(3)$ & $1(0,2)$ & 0,33 \\
\hline Knobbed acrosomes & & $0.1(0.5)$ & $0(0,0)$ & 0,3 \\
\hline Swollen acrosomes & & $0.0(0.1)$ & $0(0,0)$ & 0,1 \\
\hline
\end{tabular}

${ }^{1}$ Two bulls and 13 bulls failed to give a semen sample premating and postmating, respectively.

\section{Limitations}

In any field study using commercial herds for the source population, challenges exist in enrolling an adequate number of participating herds and avoiding selection bias. It is possible that herd managers who chose to participate were biased because of a real or perceived poor previous performance of their herd bulls. For the assessment of scrotal circumference, it would have been better to use a combination of age, breed, and live weight to categorize bulls. Insufficient data were available for dairy bulls to allow us to use that approach, and inadequate facilities were available for us to have weighed the bulls; thus, we used the age-based, non-breed-specific thresholds from the ACV guidelines (Beggs et al., 2013). More data on the rela-

Table 8. Fate of bulls during the mating period, categorized by premating overall classification

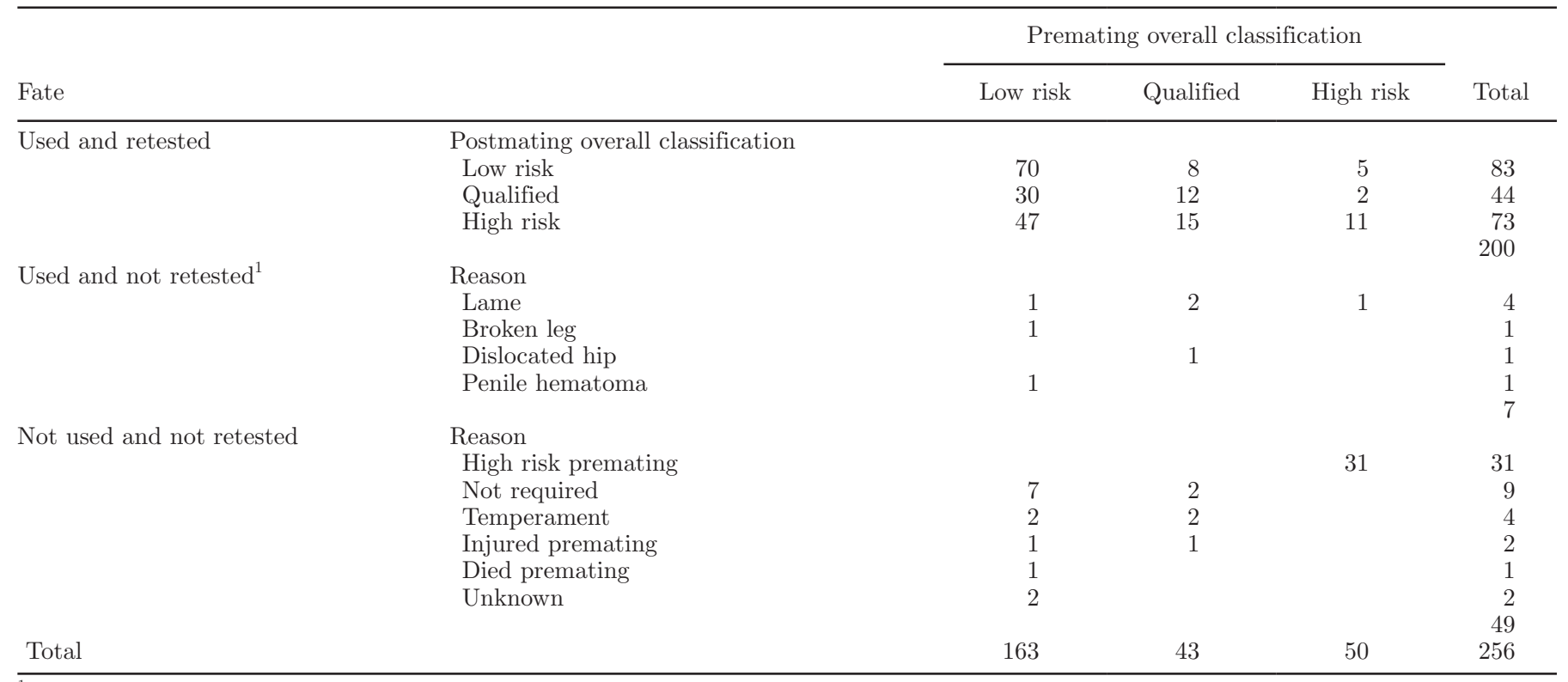

\footnotetext{
${ }^{1}$ All bulls in this category were euthanized or culled during the mating period.
} 


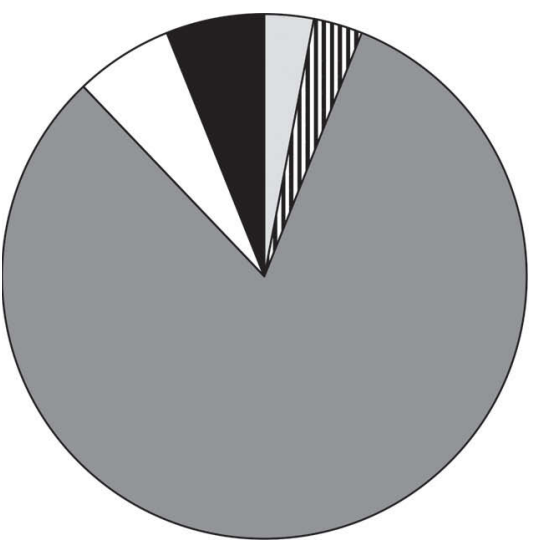

$\square$ Broken leg (3\%)

m Dislocated hip (3\%)

$\square$ Lame $(82 \%)$

$\square$ Penile injury $(6 \%)$

- Reduced libido (6\%)

Figure 4. Reasons for dairy herd bull removals during the natural mating period as reported by herd managers in southern Australia (n $=33$ ). A bull removal was defined as having occurred when the herd manager deemed that the bull was unsuitable for ongoing use and removed from the mating group for a period.

tionship between age, live weight, puberty, and scrotal circumference in dairy bulls would allow for more appropriate classification.

\section{CONCLUSIONS}

In the herds we studied, $20 \%$ of dairy herd bulls were classified as high risk on a BBSE before mating. It is likely that this high prevalence of unsoundness resulted in a higher risk of reduced fertility in these herds; therefore, we recommend that herd bulls undergo a BBSE at purchase and before each mating period. In general, dairy industry bodies should encourage more awareness of dairy herd bull soundness and health. The attrition rate of dairy herd bulls during the mating period is high, and lameness is the most significant issue affecting dairy herd bulls during mating. Anything that herd managers can do to prevent lameness in their cows is likely to improve the soundness, longevity, and fertility of their bulls.

\section{ACKNOWLEDGMENTS}

The authors acknowledge the support of the participating herds, The Vet Group (Timboon, Australia), Dairy Australia (Melbourne, Australia), Gardiner Foundation (Melbourne, Australia), the University of Melbourne (Melbourne, Australia), and Chenovet (Wagga Wagga, Australia).

\section{REFERENCES}

Acuña, C., and C. Campero. 1999. Examen clínico reproductivo en 22.994 toros de razas de carne en la pampa húmeda de Argentina. Therios Rev. Med. Vet. Prod. Anim. 28:63-75.
Al-Makhzoomi, A., N. Lundeheim, M. Håård, and H. Rodríguez-Martínez. 2008. Sperm morphology and fertility of progeny-tested AI dairy bulls in Sweden. Theriogenology 70:682-691.

Andersson, M., and M. Alanko. 1992. Relationship between testicular measurements, body weight and semen quality in young dairy bulls. Acta Vet. Scand. 33:15-20.

Argue, B., K. Chousalkar, and P. Chenoweth. 2013. Presence of Ureaplasma diversum in the Australian cattle population. Aust. Vet. J. 91:99-101.

Barth, A. D., and C. L. Waldner. 2002. Factors affecting breeding soundness classification of beef bulls examined at the Western College of Veterinary Medicine. Can. Vet. J. 43:274-284.

Beggs, D. S., J. D. Bertram, P. J. Chenoweth, K. W. Entwistle, G. Fordyce, H. Johnston, P. Johnston, M. R. McGowan, G. Niethe, S. Norman, and V. E. A. Perry. 2013. Veterinary bull breeding soundness evaluation. Queensland Australian Cattle Veterinarians, Eight Mile Plains, Australia.

Bertram, J. D., G. Fordyce, M. McGowan, G. Jayawardhana, L. Fitzpatrick, V. Doogan, J. De Faveri, and R. Holroyd. 2002. Bull selection and use in northern Australia: 3. Serving capacity tests. Anim. Reprod. Sci. 71:51-66.

Blockey, M. A., and E. Taylor. 1984. Observations on spiral deviation of the penis in beef bulls. Aust. Vet. J. 61:141-145.

Boyd, G., V. Healy, R. Mortimer, and J. Piotrowski. 1991. Serving capacity tests are unable to predict the fertility of yearling bulls. Theriogenology 36:1015-1025.

Boyd, G. W., D. D. Lunstra, and L. R. Corah. 1989. Serving capacity of crossbred yearling beef bulls. I. Single-sire mating behavior and fertility during average and heavy mating loads at pasture. J. Anim. Sci. 67:60-71.

Bruner, K., R. McCraw, M. Whitacre, and S. Van Camp. 1995. Breeding soundness examination of 1,952 yearling beef bulls in North Carolina. Theriogenology 44:129-145.

Chacón, J., E. Perez, E. Müller, L. Söderquist, and H. Rodriguez-Martinez. 1999. Breeding soundness evaluation of extensively managed bulls in Costa Rica. Theriogenology 52:221-231.

Champagne, J. D., J. H. Kirk, and J. P. Reynolds. 2002. Bull management practices on California dairies: Implications for education and veterinary services. Pages 15-21 in Proc. 15th Annual Fall Symposium, Univ. California, Davis. University of California, Davis.

Chenoweth, P. J., J. D. Champagne, and J. F. Smith. 2003. Managing herd bulls in large dairies. Pages 107-118 in Proc. 6th Western Dairy Management Conference, Reno, NV. Western Dairy Management Conference, Reno, NV.

Chesterton, R. N., K. Lawrence, and R. Laven. 2008. A descriptive analysis of the foot lesions identified during veterinary treatment for lameness on dairy farms in north Taranaki. N. Z. Vet. J. $56: 130-138$.

Chesterton, R. N., D. Pfeiffer, R. Morris, and C. Tanner. 1989. Environmental and behavioural factors affecting the prevalence of foot lameness in New Zealand dairy herds-A case-control study. N. Z. Vet. J. 37:135-142.

Coulter, G. H., and G. Kozub. 1989. Efficacy of methods used to test fertility of beef bulls used for multiple-sire breeding under range conditions. J. Anim. Sci. 67:1757-1766.

Dairy Australia. 2011. InCalf Fertility Data Project 2011. Dairy Australia, Melbourne, Australia.

De Vries, A. 2006. Economic value of pregnancy in dairy cattle. J. Dairy Sci. 89:3876-3885.

Dwyer, C. 2013a. Dairy bulls - Why and how we should be testing them. Pages 163-167 in Proc. Australian Cattle Veterinarians Conference, Darwin, Australia. The Australian Veterinary Association, St. Leonards, Australia.

Dwyer, C. 2013b. Results of an investigation into dairy herd bull breeding soundness and management in Tasmania. Pages 123-126 in Proc. Australian Cattle Veterinarians Conference, Darwin, Australia. The Australian Veterinary Association, St. Leonards, Australia.

Ellis, R. W., G. P. Rupp, P. Chenoweth, L. Cundiff, and D. Lunstra. 2005. Fertility of yearling beef bulls during mating. Theriogenology 64:657-678. 
Elmore, R., C. Bierschwal, C. Martin, and R. Youngquist. 1975. A summary of 1127 breeding soundness examinations in beef bulls. Theriogenology 3:209-218.

Farin, P. W., P. Chenoweth, D. Tomky, L. Ball, and J. Pexton. 1989 Breeding soundness, libido and performance of beef bulls mated to estrus synchronized females. Theriogenology 32:717-725.

Fitzpatrick, L. A., G. Fordyce, M. McGowan, J. Bertram, V. Doogan, J. De Faveri, R. Miller, and R. Holroyd. 2002. Bull selection and use in northern Australia: Part 2. Semen traits. Anim. Reprod. Sci. 71:39-49.

Foote, R. H., G. Seidel, J. Hahn, W. Berndtson, and G. Coulter. 1977. Seminal quality, spermatozoal output, and testicular changes in growing Holstein bulls. J. Dairy Sci. 60:85-88.

Fordyce, G., L. Fitzpatrick, N. Cooper, V. Doogan, J. De Faveri, and R. Holroyd. 2002. Bull selection and use in northern Australia: 5. Social behaviour and management. Anim. Reprod. Sci. 71:81-99.

Freneau, G. E., P. Chenoweth, R. Ellis, and G. Rupp. 2010. Sperm morphology of beef bulls evaluated by two different methods. Anim. Reprod. Sci. 118:176-181.

Godfrey, R. W., and D. Lunstra. 1989. Influence of single or multiple sires and serving capacity on mating behavior of beef bulls. J. Anim. Sci. 67:2897-2903.

Hancock, A. S., P. Younis, D. Beggs, P. Mansell, and M. Pyman. 2015. Infectious reproductive disease pathogens in dairy herd bulls. Aust. Vet. J. 93:349-353.

Hancock, A., P. Younis, D. Beggs, P. Mansell, M. Stevenson and M. Pyman. 2016. An assessment of dairy herd bulls in southern Australia: 2. Analysis of bull and herd level risk factors and their associations with pre- and post-mating breeding soundness results. J. Dairy Sci. 99:9998-10008. http://dx.doi.org/10.3168/jds.201510792.

Harris, D. J., C. Hibburt, G. Anderson, P. Younis, D. Fitspatrick, A. Dunn, I. Parsons, and N. McBeath. 1988. The incidence, cost and factors associated with foot lameness in dairy cattle in southwestern Victoria. Aust. Vet. J. 65:171-176.

Hoflack, G., A. Van Soom, D. Maes, A. De Kruif, G. Opsomer, and L. Duchateau. 2006. Breeding soundness and libido examination of Belgian Blue and Holstein Friesian artificial insemination bulls in Belgium and the Netherlands. Theriogenology 66:207-216.

Holroyd, R. G., V. Doogan, J. De Faveri, G. Fordyce, M. McGowan, J. Bertram, D. Vankan, L. Fitzpatrick, G. Jayawardhana, and R. Miller. 2002. Bull selection and use in northern Australia: 4. Calf output and predictors of fertility of bulls in multiple-sire herds. Anim. Reprod. Sci. 71:67-79.

InCalf. 2008. Bulls power up! Adviser Handbook. Dairy Australia, Melbourne, Australia.

Jubb, T. F., and J. Malmo. 1991. Lesions causing lameness requiring veterinary treatment in pasture-fed dairy cows in East Gippsland. Aust. Vet. J. 68:21-24.

Kastelic, J. P., and J. Thundathil. 2008. Breeding soundness evaluation and semen analysis for predicting bull fertility. Reprod. Domest. Anim. 43:368-373.

Kennedy, S. P. 2002. Breeding soundness evaluations of 3648 yearling beef bulls using the 1993 Society for Theriogenology guidelines. Theriogenology 58:947.

Lehrer, A. R., M. B. Brown, H. Schindler, Z. Holzer, and B. Larsen. 1977. Paternity tests in multisired beef herds by blood grouping. Acta Vet. Scand. 18:433-441.

Lima, F. S., C. Risco, M. Thatcher, M. Benzaquen, L. Archbald, J. Santos, and W. Thatcher. 2009. Comparison of reproductive performance in lactating dairy cows bred by natural service or timed artificial insemination. J. Dairy Sci. 92:5456-5466.

Lima, F. S., A. De Vries, C. A. Risco, J. E. P. Santos, and W. W Thatcher. 2010. Economic comparison of natural service and timed artificial insemination breeding programs in dairy cattle. J. Dairy Sci. 93:4404-4413.

Makarechian, M., A. Farid, and R. Berg. 1987. Evaluation of bull fertility in multiple-sire mating at pasture. Can. J. Anim. Sci. $67: 27-35$
McDiarmid, J. J. 1981. "Corkscrew penis" and other breeding abnormalities in beef bulls. N. Z. Vet. J. 29:35-36.

McGowan, M. R., J. Bertram, G. Fordyce, L. Fitzpatrick, R. Miller, G. Jayawardhana, V. Doogan, J. De Faveri, and R. Holroyd. 2002 Bull selection and use in northern Australia: 1. Physical traits. Anim. Reprod. Sci. 71:25-37.

Menegassi, S. R. O., J. O. J. Barcellos, V. N. Lampert, J. B. S. Borges, and V. Peripolli. 2011. Bioeconomic impact of bull breeding soundness examination in cow-calf systems. Rev. Bras. Zootec. 40:441-447.

Menegassi, S. R. O., J. O. J. Barcellos, V. Peripolli, J. B. S. Borges, and M. L. Bernardi. 2012. Causes of rejection of beef bulls in breeding soundness evaluation. Rev. Bras. Zootec. 41:1648-1653.

Morton, J. M. 2010. Interrelationships between herd-level reproductive performance measures based on intervals from initiation of the breeding program in year-round and seasonal calving dairy herds. J. Dairy Sci. 93:901-910.

Murray, R. D., D. Downham, M. Clarkson, W. Faull, J. Hughes, F. Manson, J. Merritt, W. Russell, J. Sutherst, and W. Ward. 1996. Epidemiology of lameness in dairy cattle: description and analysis of foot lesions. Vet. Rec. 138:586-591.

Nöthling, J. O., and P. Irons. 2008. A simple multidimensional system for the recording and interpretation of sperm morphology in bulls. Theriogenology 69:603-611.

Osterhoff, D. R. 1966. Recent developments in blood-group studies in domestic animals. Proc. S. Afr. Soc. Anim. Prod. 5:174-185.

Overton, M. W. 2005. Cost comparison of natural service sires and artificial insemination for dairy cattle reproductive management. Theriogenology 64:589-602.

Overton, M. W., and W. M. Sischo. 2005. Comparison of reproductive performance by artificial insemination versus natural service sires in California dairies. Theriogenology 64:603-613.

Petherick, J. 2005. A review of some factors affecting the expression of libido in beef cattle, and individual bull and herd fertility. Appl. Anim. Behav. Sci. 90:185-205.

Risco, C.. F. Lima, and J. E. Santos. 2011. Management Considerations of Natural Service Breeding Programs in Dairy Herds. Vol. 2015. Accessed Oct. 10, 2013. http://extension.vetmed.ufl.edu/ files/2012/04/Management-Considerations-of-Natural-ServiceBreeding-Programs-in-Dairy-Herds_Risco.pdf.

Risco, C. A., P. J. Chenoweth, B. I. Smith, J. S. Velez, and R. Barker. 1998. Management and economics of natural service bulls in dairy herds. Pages 385-390 in Compendium on Continuing Education for the Practising Veterinarian-North American edition. Vol. 20 Veterinary Learning Systems, Ewing, NJ.

Roche, J. R., K. Macdonald, C. Burke, J. Lee, and D. Berry. 2007. Associations among body condition score, body weight, and reproductive performance in seasonal-calving dairy cattle. J. Dairy Sci. 90:376-391.

Smith, M. F., D. Morris, M. Amoss, N. Parish, J. Williams, and J. Wiltbank. 1981. Relationships among fertility, scrotal circumference, seminal quality, and libido in Santa Gertrudis bulls. Theriogenology 16:379-397.

Tarlton, J. E., D. Holah, K. Evans, S. Jones, G. Pearson, and A. Webster. 2002. Biomechanical and histopathological changes in the support structures of bovine hooves around the time of first calving. Vet. J. 163:196-204.

Tranter, W. P., and R. Morris. 1991. A case study of lameness in three dairy herds. N. Z. Vet. J. 39:88-96.

Waldner, C. L., R. I. Kennedy, and C. W. Palmer. 2010. A description of the findings from bull breeding soundness evaluations and their association with pregnancy outcomes in a study of western Canadian beef herds. Theriogenology 74:871-883.

Westwood, C. T., E. Bramley, and I. Lean. 2003. Review of the relationship between nutrition and lameness in pasture-fed dairy cattle. N. Z. Vet. J. 51:208-218.

Woolaston, R., and R. Shephard. 2011. Improvement of the reproductive performance of Victorian dairy herds. Gardiner Foundation, Melbourne, Australia. 